\title{
Arquivos pessoais de professores: o que guardam e o que nos dizem?
}

Personal files of teachers: what do they keep and what do they tell us?

Archivospersonales de los profesores: ¿qué guardan y qué nos dicen?

\author{
Libânia Nacif Xavier \\ Universidade Federal do Rio de Janeiro (Brasil) \\ https://orcid.org/0000-0003-4422-2118 \\ http://lattes.cnpq.br/1009093134243267 \\ libanianacif@gmail.com \\ Mychelle Nelly Maia Robert \\ Universidade Federal do Rio de Janeiro (Brasil) \\ https://orcid.org/0000-0003-4545-6979 \\ http://lattes.cnpq.br/6934428044536567 \\ michellerobert@gmail.com
}

\section{Resumo}

O artigo se remete ao Arquivo Pessoal do Professor Rubin Santos Leão de Aquino (1929-2013): professor de história de cursinhos pré-vestibulares da zona sul da cidade do Rio de Janeiro e ativo mediador intelectual, tendo atuado em programas de rádio; sindicatos e entidades dedicadas à luta em defesa dos direitos políticos, durante o regime militar. Está dividido em quatro seções: a primeira reflete sobre a natureza dos arquivos pessoais de professores da educação básica; a segunda descreve o conteúdo do Arquivo em questão; a terceira articula as características pessoais de seu detentor com as marcas próprias de uma cultura profissional atinente aos professores de história do ensino médio; a quarta e última seção aponta os indícios e desafios que emergiram nas pesquisas que foram tecidas no diálogo entre a organização arquivística e as atividades de pesquisa com essas fontes documentais.

Palavras-chave: Arquivos pessoais. Professores da educação básica. História da profissão docente. 


\begin{abstract}
The article refers to the Personal Archive of Professor Rubin Santos Leão de Aquino (19292013): professor of history of pre-university entrance courses in the south zone of the city of Rio de Janeiro and active intellectual mediator, having worked in radio programs; unions and entities dedicated to the struggle to defend political rights during the military regime. It is divided into four sections: the first reflects on the nature of the personal files of teachers of basic education; the second describes the contents of the Archive in question; the third articulates the personal characteristics of its holder with the marks of a professional culture related to high school history teachers; the fourth and last section points to the evidence and challenges that emerged in the research that were woven into the dialogue between the archival organization and the research activities with these documentary sources.
\end{abstract}

Keywords: Personal archives. Basic education teachers. History of the teaching profession.

\title{
Resumen
}

El artículo hace referencia al Archivo Personal del Profesor Rubin Santos Leão de Aquino (1929-2013): profesor de historia de los cursos de ingreso preuniversitario en la zona sur de la ciudad de Río de Janeiro y mediador intelectual activo, habiendo trabajado en programas de radio; sindicatos y entidades dedicadas a la lucha por la defensa de los derechos políticos durante el régimen militar. Se divide en cuatro apartados: el primero reflexiona sobre la naturaleza de los archivos personales de los docentes de educación básica; el segundo describe el contenido del Archivo en cuestión; el tercero articula las características personales de su titular con las marcas de una cultura profesional relacionada con los profesores de historia de secundaria; la cuarta y última sección apunta a las evidencias y desafíos que surgieron en la investigación que se entretejieron en el diálogo entre la organización archivística y las actividades de investigación con estas fuentes documentales.

Palabras clave: Archivos personales. Profesores de educación básica. Historia de la profesión docente. 


\section{Arquivos pessoais de professores: o que guardam e o que nos dizem?}

O artigo tece algumas considerações sobre o Arquivo Pessoal do Professor Rubin Santos Leão de Aquino (1929-2013). Aquino foi professor de história de cursinhos prévestibulares da zona sul da cidade do Rio de Janeiro e, embora se dedicasse a esta atividade em tempo integral, ele também atuou em diversos outros espaços de mediação intelectual, tais como programas de rádio; atividades culturais em sindicatos; participação em entidades dedicadas à luta em defesa dos direitos de familiares de mortos e desaparecidos durante o regime militar, tais como a Anistia Internacional e o Grupo Tortura Nunca Mais. Além disso, ele ostentava duas paixões: o futebol do Flamengo e a Escola de Samba da Mangueira. Ao longo de sua vida, este professor acumulou um vasto conjunto documental que reúne uma gama variada de registros, tendo em vista aa múltiplas atividades que ele desenvolveu. Porém, nesse artigo, nós vamos tratar apenas dos documentos da parte pedagógica de seu Arquivo.

Receber o Arquivo pessoal de um professor de história que foi referência para as gerações de professores que atuaram nas escolas de educação básica do Rio de Janeiro trouxe a oportunidade de acompanhar uma trajetória ímpar, como nos revelam os indícios guardados no referido Arquivo. Porém, se a exploração dos documentos que o compõem nos permitem observar a história individual do titular, eles também revelam os constrangimentos, as expectativas e esperanças da geração de professores dos anos 1960 90 que, como ele, se engajaram na construção de uma sociedade democrática, articulando o seu trabalho a essa luta. Cumpre destacar que os livros didáticos de autoria do professor Aquino marcaram as trajetórias de professores e alunos, que se recordam do impacto que estes causaram, fugindo ao padrão de livros didáticos em circulação, nos anos 1980-90. Tem sido comum, também, ouvir relatos de seus ex-alunos, muitos dos quais nos contam que a decisão de seguir a carreira de historiadores foi tomada, em grande medida, inspiradas no exemplo deste professor.

Feitas as apresentações iniciais, adiantaremos a estrutura do presente artigo, que está dividido em quatro seções: a primeira apresenta o nosso ponto de vista sobre a natureza dos Arquivos Pessoais de Professores da Educação Básica; a segunda descreve o conteúdo do Arquivo em questão; a terceira articula as características pessoais de seu detentor com as marcas próprias de uma cultura profissional atinente aos professores de história do ensino médio; a quarta e última seção apresenta alguns indícios e desafios que emergiram na pesquisa para redação da tese de titular e, também, para a dissertação de mestrado das autoras. As observações aqui reunidas foram tecidas a partir do diálogo entre o trabalho de organização arquivística e o desenvolvimento das atividades de pesquisa com essas fontes documentais.

\section{Arquivos pessoais de professores da educação básica}

Iniciamos esta seção afirmando que é algo incomum encontrar arquivos pessoais de professores (as) da educação básica, organizados institucionalmente e abertos à consulta pública. Por outro lado, cremos não ser incomum encontrar arquivos organizados pelos próprios professores, em suas casas. As duas constatações sugerem algumas hipóteses que as explicam. Em primeiro lugar, deve-se levar em conta que a profissão docente se constitui como uma atividade de divulgação e se dirige a um público tanto mais amplo quanto mais democrático for o acesso à educação escolar no país. Tal tarefa demanda uma gama variada de dados e informações, bem como a experimentação de diferentes estratégias de mediação dos conhecimentos científicos.

Por outro lado, a profissão de professor da educação básica também constitui uma atividade desempenhada por um numeroso grupo de profissionais que devem se empenhar 
para forjar uma comunicação palatável para um público numeroso e heterogêneo, constituído, para grande parte dos docentes, de crianças e jovens. Por suas condições de trabalho, os professores da educação básica lidam com uma tremenda fragmentação e expropriação de seu tempo ${ }^{1}$, com jornadas em vários turnos e múltiplas turmas, lidando, muitas vezes, com diferentes especificidades etárias. Estas, por sua vez, apresentam demandas de aprendizado e de conteúdos curriculares também diversos, o que provoca dispersão e gera grandes desafios profissionais.

Desse modo, os professores desenvolvem um trabalho de mediação intelectual que os coloca como divulgadores de conhecimentos produzidos por outrem. Concordamos com Gomes e Hansen (2016), no que se refere à complexidade e importância dos trabalhos voltados para a mediação cultural, ainda que reconheçamos a força simbólica das hierarquias que circulam no ambiente acadêmico.

Acreditamos que, por esses motivos, seja rara a preservação de arquivos de professores da educação básica em instituições de guarda ${ }^{2}$. Acrescente-se o fato desses intelectuais mediadores $^{3}$ - que são os professores -, não terem tempo disponível para o registro de seu trabalho ou para refletirem sobre este. Com isso, acabam por manter uma certa invisibilidade a respeito da relevância e complexidade das formas de produção e mediação de conhecimentos que eles promovem, bem como dos resultados do trabalho que realizam. Por fim, cabe lembrar que os resultados do trabalho dos professores, via de regra, só podem ser medidos no médio e longo prazo, já que eles lidam com seres humanos e que fatores os mais imprevistos e imperceptíveis a olho nu interferem na condução de seu trabalho.

Em síntese, podemos afirmar que enquanto produtores de um tipo de conhecimento específico - o conhecimento escolar - esses professores criam sínteses que articulam conteúdos de diferentes campos disciplinares - como, no caso em estudo, a história e a historiografia; a didática e as metodologias de ensino de história; o debate político e pedagógico; os conteúdos temáticos do currículo escolar nos diferentes níveis de ensino; conhecimentos de psicologia e comunicação, entre outros. Tudo isso para tornar os conteúdos a serem ensinados mais atrativos de acordo com o interesse e os níveis de desenvolvimento cognitivo do público escolar, tendo que adequar a sua obra de mediação intelectual (o que muitos chamam de tarefas práticas) às necessidades do momento. Cabe lembrar, ainda, que cada aluno e cada turma possuem caraterísticas muito particulares e que o bom entrosamento entre professor e alunos requer, justamente, atenção para estabelecer uma sintonia fina nessa relação, o que demanda uma boa dose de afetividade.

Nesse aspecto, é forçoso registrar os avanços proporcionados à percepção das especificidades da produção intelectual dos professores da educação básica, com base nos estudos de Maurice Tardiff (2010). O autor nos mostra que os saberes docentes são temporais, plurais e heterogêneos, ecléticos e sincréticos, personalizados e situados. Com isso, nos oferece uma intepretação positiva - que evita qualificar o saber docente pelo que ele não é, pelas características que ele não apresenta em relação aos saberes científicos e acadêmicos, por exemplo. Isso nos habilita a perceber os documentos preservados nos Arquivos pessoais de professores da educação básica, considerando as suas especificidades e avaliando o seu valor como materialização de um complexo trabalho de mediação intelectual, original e criativo.

Então, chegamos à conclusão de que o valor atribuído aos documentos guardados no arquivo pessoal de um professor da educação básica requer um interesse muito

\footnotetext{
${ }^{1}$ Sobre as dimensões do tempo presentes na organização do trabalho dos professores da educação básica ver os estudos de Silva (2017) e Bahia (2016).

2 Ainda que cada instituição de guarda adote critérios específicos para selecionar os Arquivos sob sua responsabilidade, pode-se afirmar que, de maneira geral, os Arquivos pessoais visados são aqueles cujos titulares exerceram cargo público ou foram acadêmicos e artistas de renome.

${ }^{3}$ Sobre o conceito de intelectuais mediadores, ver J. F. Sirinelly (1989); Gomes e Hansen (2016).
} 
específico. No nosso caso, nós partilhamos o interesse em apreender o que faz e como faz um professor para desempenhar o seu papel e cumprir a sua função profissional. Para se interessar pela sua obra - uma obra produzida por tantos outros profissionais com igual função - e também por suas maneiras de produzir - algo tão pouco visível, encoberto na correria para dar conta do tempo e atender a tudo e a todos - é necessário ver a sua complexidade e relevância, para além das aparências.

Nossa experiência com a organização e exploração dos documentos do Arquivo pessoal do Professor Aquino nos levou a pensar essas questões a partir do modo artesanal com que esse professor constituiu a sua memória e o seu legado. Para Mills (2009) o arquivo pessoal de um cientista social (algo que a nosso ver pode-se estender ao arquivo de um professor) expressa, acima de tudo, o modo como ele se constituiu como profissional e como pessoa.

Isso tudo para dizer que os documentos guardados por professores (as) da educação básica tendem a tornar o seu arquivo extremamente pessoal e, ao mesmo tempo, corriqueiro. Pessoal, porque reúne documentos, textos, livros, anotações, diários de classe, entre outros itens, que só a ele interessam e que se destinam a guardar informações úteis durante um ano letivo, podendo perder sua utilidade no ano seguinte.

Por outro lado, os documentos guardados nos arquivos desses professores, muitas vezes, parecem ser atemporais. Ou seja, não exibem suas temporalidades de modo preciso, a não ser pelo tipo de suporte utilizado para produzi-los. No caso do Arquivo em tela, há muitas cópias de textos utilizados em sala de aula, dando mostras de que um bom texto era utilizado em várias turmas por vários anos consecutivos, o que explica a inexistência de cabeçalhos e, por vezes, a colagem de trechos de um texto novo, bem como de tópicos de outro roteiro para guiar a explicação a ser transmitida na aula do dia. Tais imprecisões, por assim dizer, geraram algumas dúvidas a serem superadas pela equipe que se dedicou à organização do referido arquivo, conforme veremos na secção que se segue, que versará sobre a composição e as questões que surgiram ao longo do trabalho de descrição dos itens arquivados.

\section{O Arquivo Pedagógico}

A parte pedagógica do Arquivo do professor Aquino foi recebida ${ }^{4}$ em 20.04.2017. Imediatamente, nós iniciamos a organização daquela documentação, começando pelas pastas que reuniam documentos utilizados nos Colégios em que ele atuou. Sobre esse trabalho, é importante destacar o quanto se tornou fértil o esforço de buscar a categoria que melhor descrevia cada item para registro no catálogo dos documentos do acervo. Seguindo a norma brasileira de descrição arquivística, a equipe de graduandos em atividades de iniciação científica, sob nossa coordenação e com a supervisão da arquivista da instituição ${ }^{5}$ realizou a identificação e agrupamento dos documentos, compondo um catálogo preliminar. Em seguida, passamos para a higienização e acondicionamento adequado das imagens, sendo a etapa seguinte composta pelo trabalho de classificação e higienização, para posterior registro, dos livros que compõem a sua biblioteca pedagógica.

Luciana Heymann (1997) destaca as tensões que permeiam a constituição de um arquivo privado, destacando a seleção realizada por seu detentor, que guarda e descarta os resíduos de acordo com a memória que melhor espelha as marcas de identidade que ele valoriza. Além da interferência do próprio titular na composição do seu arquivo, a autora lembra que outras intervenções se sucedem, sobretudo depois de seu falecimento, seja por parte da família, que reorganiza a documentação de modo a compatibilizar condições como espaço e modo de

\footnotetext{
${ }^{4}$ A parte pedagógica do Arquivo encontra-se preservada no Programa de Estudos e Documentação Educação e Sociedade / Proedes/UFRJ.

${ }^{5}$ No Proedes-UFRJ, a organização do Arquivo foi coordenada por Michele Almeida, com a colaboração da então mestranda Michelle Robert e das bolsistas de Iniciação Científica Mariana Correa e Mariana Vieira, sob minha supervisão.
} 
acondicionamento para posterior transferência da documentação, assim como as que são realizadas pelas instituições de guarda que, ao receberem o arquivo, o submetem às normas técnicas requeridas.

De fato, como já assinalamos, a coleção de documentos que estamos focalizando neste artigo é uma pequena parte de um conjunto documental bem maior e mais diversificado. Nesse recorte pedagógico, encontramos livros de sua autoria; materiais levantados para a redação das publicações e para preparação de aulas, com destaque para ilustrações, mapas e charges; algumas correspondências institucionais e muitos roteiros, resumos, planos de aula e apostilas de diferentes escolas nas quais ele atuou; comentários sobre filmes; dossiês temáticos, entre outros itens. Os documentos já chegaram com a organização que havia sido dada por seu autor, posteriormente ajustada pela organização feita pelos herdeiros, com o auxílio de uma amiga da família que é profissional da área de história e biblioteconomia ${ }^{6}$. Essa organização prévia nos facilitou a acesso e manuseio dos itens, respeitando, na medida do possível, o arranjo do titular.

A extensão do arquivo levou a que seus herdeiros decidissem fragmentar o conjunto documental, de modo a facilitar sua distribuição por diferentes instituições de guarda ${ }^{7}$. Isto denota outra característica, que é a sua variedade. Mesmo tendo trabalhado com apenas uma parte do amplo conjunto documental, foi possível perceber uma clara articulação e integração dos registros das diferentes ações e ambições que desenham a trajetória do titular. O fato de saber o conteúdo das outras partes que compõem o conjunto, certamente, contribuiu para essa visão. Nessa perspectiva, cabe destacar a importância dos demais Centros de documentação promoverem a mais ampla divulgação sobre a localização das partes do acervo que se encontram sob sua guarda, permitindo que os pesquisadores se habilitem a promover uma intepretação integrada dos vestígios que compõem a totalidade do Arquivo legado pelo titular.

Ao longo do trabalho de organização documental, ficou claro para a equipe, o modo por meio do qual Aquino se estruturou como professor de história e desempenhou as funções que o ofício lhe demandava. A observação de alguns conjuntos documentais nos permitiu dialogar com os procedimentos que ele adotou visando a preparação das aulas e a comunicação com os alunos. No que tange aos nossos interesses de pesquisa, a intenção foi a de captar as particularidades e os modos comuns ao exercício da docência que emergiram de nossa leitura desse material.

Existem resumos, planos e roteiros de aula, sumários com notas manuscritas, listas de conteúdos acompanhados de recortes de jornal, entre muitos outros modos de organizar a massa de informações a ser transmitida aos alunos. Estes documentos demonstram o que os professores fazem (a partir do exemplo do que fazia Aquino) para tornarem conteúdos extremamente complexos, compreensíveis para os alunos. Os roteiros de preparação das suas aulas se repetiam em diferentes suportes de reprodução (mimeografados, datilografados, xerocados, impressos com jato de tinta, a lazer, etc.). Isso mostra que, ao constituir seu acervo, o professor Aquino viveu um momento de transição tecnológica em que os suportes digitais começaram a aparecer, dando a ver a presença de algum hibridismo no material arquivado.

Como já assinalamos, essas repetições dos roteiros de aula - que compreendiam uma lista articulada de eventos que marcavam os processos históricos em estudo -

\footnotetext{
${ }^{6}$ Suprimido o nome da historiadora e profissional da biblioteconomia, amiga da família.

${ }^{7}$ Os demais conjuntos documentais foram distribuídos pela família de modo a contribuir para posterior disponibilização à consulta pública em instituições de guarda pertinentes, tais como o Arquivo Público do Estado do Rio de Janeiro (APERJ), que recebeu a documentação relativa às pesquisas sobre a Ditadura Militar no Brasil e à sua atuação no Comitê Pró Anistia e no Grupo Tortura Nunca Mais; o Museu de Arte Moderna (MAM), que recebeu livros e DVDs de seu acervo; o Museu da República, que recebeu todo o material relativo à República; o Departamento de América Latina da PUC-Rio, que abrigou os documentos relativos a esta região e o Centro de Ciências Humanas da Universidade do Recôncavo Baiano (UFRB) que recebeu cerca de 700 itens entre livros e vídeos.
} 
demonstra que era grande a quantidade de turmas para as quais ele ministrava aulas, sem falar da quantidade de alunos que, em alguns cursos chegavam ao total de 200 alunos em sala de aula, conforme depoimento do próprio. ${ }^{8}$

Nesse sentido, as características assinaladas demonstram uma espécie de modus operandido trabalho de mediação intelectual que Aquino desenvolveu, sublinhando, ainda, a sua complexidade. Como observaram Gomes e Hansen (2016, p. 32-33):

o trabalho do mediador, mesmo quando entendido como "simplificação / didatização, de códigos, linguagens e conhecimentos, nada tem de fácil. O simples adquire uma gama de significados complexos, assentados nas ideias de seleção e escolha cuidadosas; de uma depuração que torna precisos os sentidos mais importantes daquilo que se deseja comunicar, o que demanda competências e vivências específicas e especializadas.

No entanto, à primeira vista, alguns documentos parecem ter pouca importância, já que boa parte das pastas reúne materiais por assim dizer, corriqueiros, que eram replicados incessantemente. Constituem, assim, sobras de materiais utilizados em sala de aula, carregando, portanto, as marcas pessoais do professor que com eles se orientava. Além disso, podem estar ultrapassados, já que a história e o conhecimento que a explica são extremamente dinâmicos.

Portanto, para um olhar mais voltado para a organização, sem o objetivo propriamente de pesquisa, esses documentos poderiam compor o lixo histórico, ou seja, poderiam ter sido eliminados, inclusive, por seu formato extremamente informal, já que muitos roteiros de aula não tinham sequer data ou cabeçalho que identificasse a que instituição pertenciam. Se o lixo histórico se remete a todo documento que não parece merecer ser guardado, produzindo-se, assim, como fonte histórica, importa perceber que, sob uma aparência de objeto sem valor histórico, esses roteiros potencializaram muitas inferências da equipe a respeito das artes de ensinar ${ }^{9}$. O debate em torno à sua importância ou opção pelo descarte permitiu, inclusive, a reflexão sobre múltiplas possibilidades de descrição dos mesmos, em diálogo com as normas de organização arquivística.

Na biblioteca pedagógica, ${ }^{10}$ encontramos livros originados de dissertações e teses que analisavam as belas mentiras contadas nos livros didáticos, assim como aqueles que se propunham a desvelar as ideologias a estes subjacentes. ${ }^{11}$ A esse respeito, há também, entre os documentos datilografados, alguns estudos que o titular desenvolveu sobre os livros didáticos em circulação, desde a época de sua formação universitária até os anos 1990/2000.

Podemos concluir, desse modo, que os Arquivos pessoais de professores da educação básica, em geral, e a parte relativa à Biblioteca Pedagógica do Arquivo do Professor Aquino, em particular, podem oferecer excelentes contribuições para os estudos

\footnotetext{
${ }^{8}$ Um tempo para não esquecer: depoimento concedido a Mário Lúcio de Paula e Patrik Granja. Nova Democracia. Ano IX, n.06, junho de 2010. Disponível em: http://anovademocracia.com.br/no-66/2836-umtempo-para-nao-esquecer\#n2. Acesso em 26. abr. 2018.

${ }^{9}$ Utilizamos o termo artes de ensinar em referência a Michel de Certeau (2009), para quem os sujeitos ordinários, isto é, aqueles que não ocupam lugares de poder, não se reduzem a meros reprodutores dos discursos, normas e prescrições que lhes são impostas, mas agem como agentes que reinterpretam esses discursos e normas, no usufruto no seu cotidiano, desenvolvendo suas artes de fazer.

${ }^{10}$ A Biblioteca encontra-se composta por 322 itens, entre livros didáticos e acadêmicos; apostilas e panfletos, coletâneas de texto e seleta de documentos, Atlas e Dicionários, entre outros. Nota-se a forte presença de livros didáticos e de história de nacionalidade francesa.

${ }^{11}$ Referência aos livros: DEIRÓ, Maria de Lourdes Chagas. As belas mentiras: a ideologia subjacente aos textos didáticos. São Paulo: Moraes, 1978; e FARIA, Ana Lucia G. Ideologia no livro didático.16. ed. São Paulo: Cortez, 2008.
} 
na área de história da educação e do currículo, da educação histórica e do ensino de história, bem como da profissão docente.

\section{O Arquivo: marcas do titular e da profissão}

Outros documentos nos permitem acompanhar o processo de elaboração dos livros didáticos, contendo provas e ajustes que fazem parte desse processo. Merece registro o conjunto de ilustrações e os mapas preparados para compor os livros didáticos de sua autoria, bem como as charges e outras modalidades de ilustração que dialogam diretamente com a sua produção autoral. A utilização de charges nos livros didáticos é uma marca muito particular do Professor Aquino, tendo em vista as possibilidades que ele vislumbrou na articulação entre textos, desenho e humor, provavelmente imaginando ser possível, com essa mistura, quebrar o preconceito que os alunos nutriam em relação à história decoreba - transmitida com base na sucessão da fatos e datas - apartada da experiência e dos interesses das crianças e adolescentes com os quais ele convivia no compartilhamento dos papéis de professor e alunos.

Desse modo, ele articula diferentes tipos de textos, documentos e ilustrações, criando condições para que os sujeitos da história fossem vistos como seres humanos, iguais aos seus leitores. Esses personagens expressam as angustias, ambições e dúvidas das pessoas comuns que, ao fim e ao cabo, falavam mais do contexto histórico em que essas pessoas viviam. Como nas charges que reproduzimos a seguir, ele personificou o Brasil - magro e acabado pela exploração institucionalizada pelo Pacto Colonial. Este último se faz presente da maleta do médico, bem nutrido e de fisionomia portuguesa.

Figura 1- Charge encomendada pelo Professor Aquino para ilustrar os livros didáticos de sua autoria.

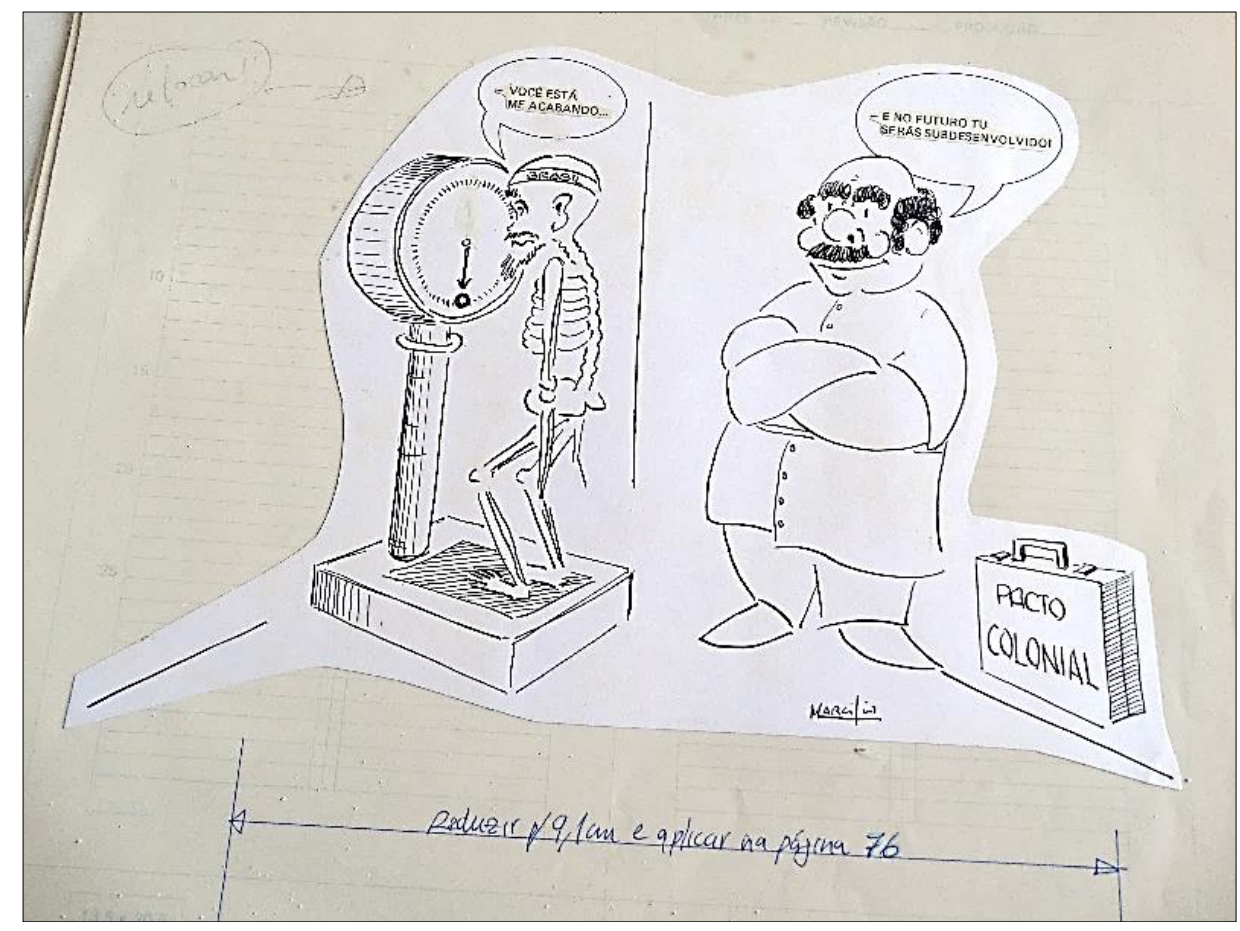

Fonte: Arquivo Aquino - Proedes / UFRJ.

$\mathrm{Na}$ charge que se segue, ele armou um insólito diálogo entre clero, nobreza e burguesia para abordar o Absolutismo de Direito Divino, aproveitando, ainda, para tocar na questão da censura, que se encontra meio escondida, com vergonha de sua função. 
Figura 2- Charge encomendada pelo Professor Aquino para ilustrar os livros didáticos de sua autoria.

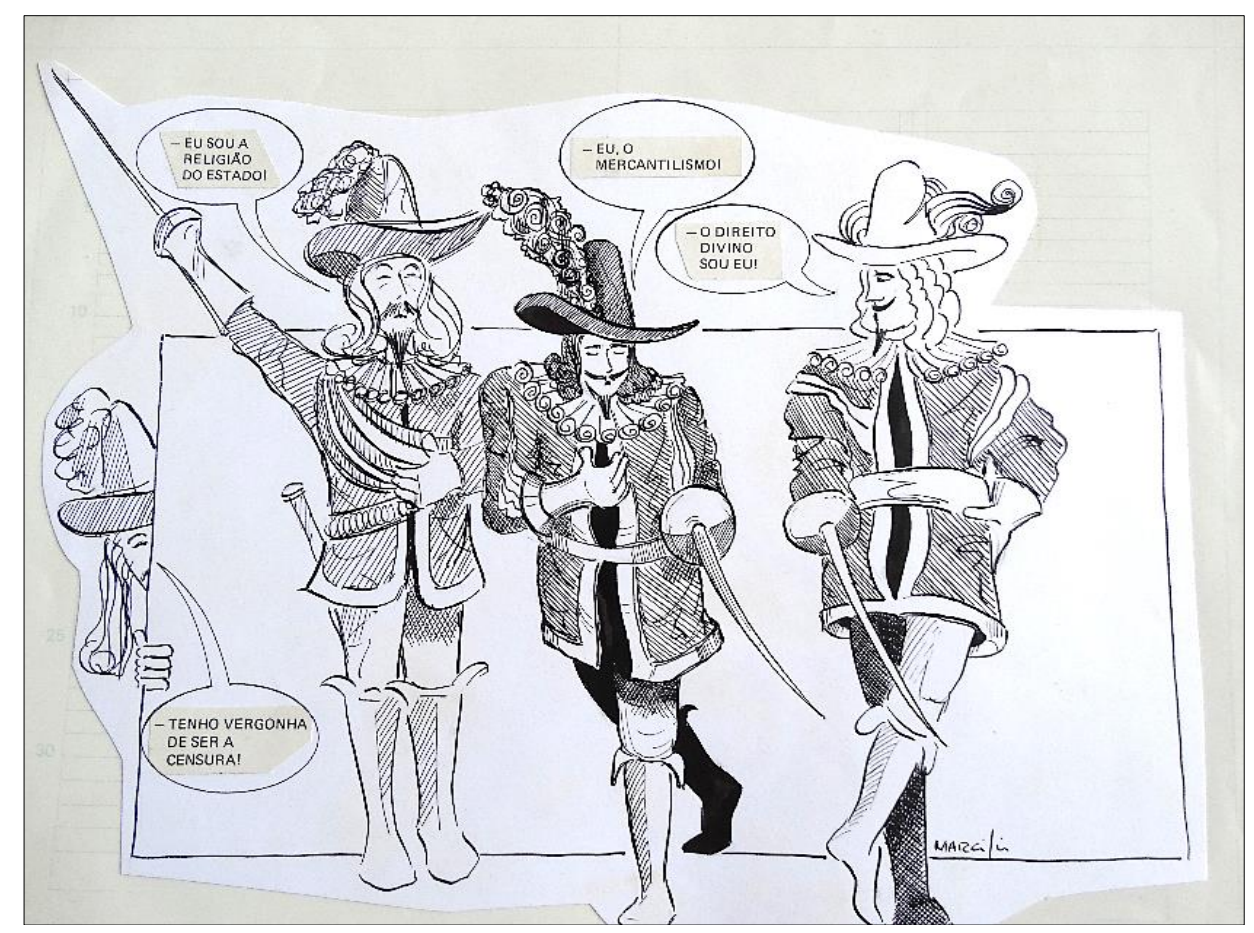

Fonte: Arquivo Aquino / Proedes - UFRJ.

Outro aspecto que pode ser visto como uma marca pessoal do modo de promover o ensino de história do Professor Aquino mas, que também pode ser visto como expressão coletiva das estratégias que outros professores de história da educação básica mobilizam, foram as marcas inseridas em alguns livros, por meio de rabiscos, colagens de matérias de jornal sobre o livro ou o assunto ali tratado, deixando registros de sua interação com esse material, por meio de práticas de leitura / seleção / classificação / apensamento e marcações escritas. Estas marcas da passagem do titular na interação com os itens arquivados, certamente indiciam os percursos de preparação de aulas e o trabalho de composição de textos que se tornavam publicações, materializando-se, tanto nos roteiros de aula e nos compêndios que ele organizava, quanto em sua obra autoral, tais como apostilas, livros didáticos, livros sobre temas de sua preferência - como o futebol e os movimentos insurgentes - e artigos em coletâneas.

As fotos reproduzidas a seguir são de um livro paradidático sobre a Conjuração Mineira, em que Aquino é coautor. Já na primeira página, encontramos uma marcação em vermelho, corrigindo o seu próprio nome e, nas páginas internas, encontramos as marcas de revisão e de agregação de novos conteúdos por meio de colagens, como uma lista, em papel jornal, com as reivindicações dos conjurados e a informação sobre Hipólita, a única inconfidente mulher, provavelmente desconhecida pelos autores até o momento em que o livro foi lançado. 
Figura 3 -Um sonho de liberdade.

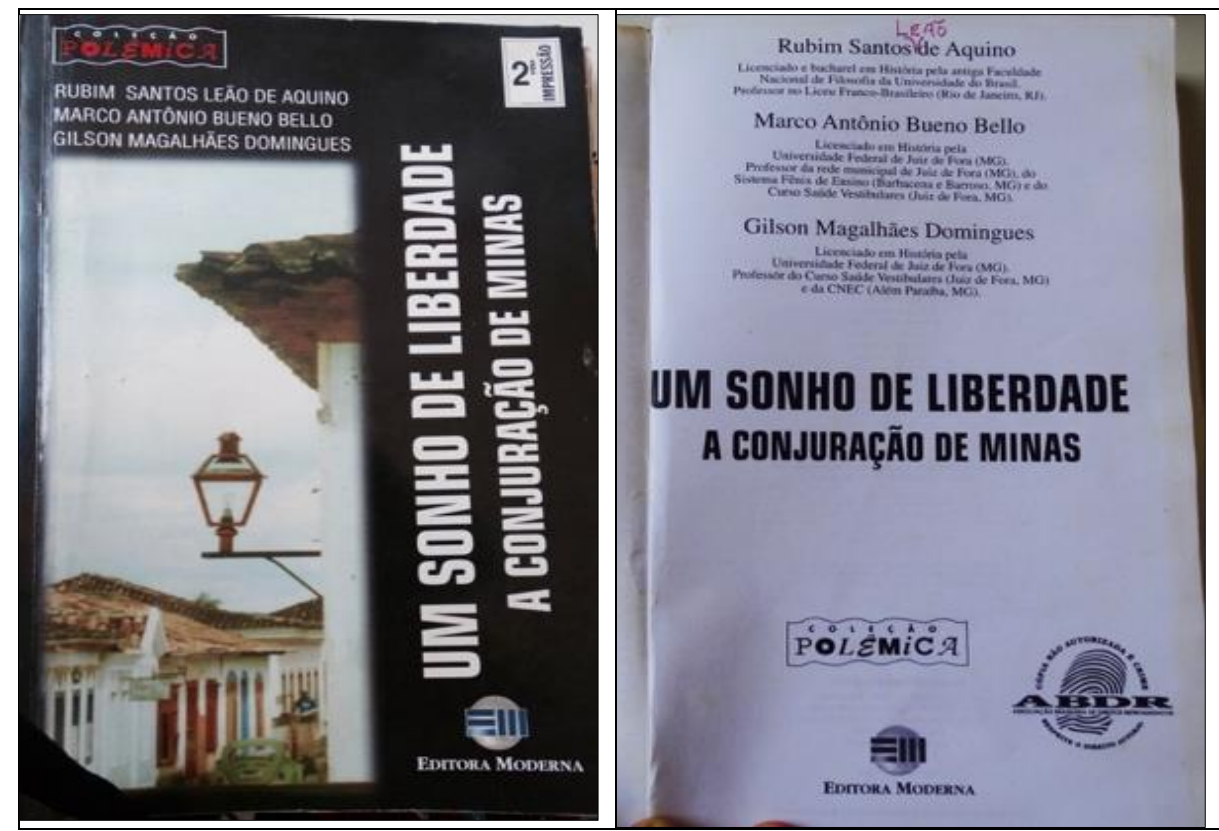

Fonte: Os autores.

Figura 4 - Arquivo Aquino - biblioteca pedagógica.

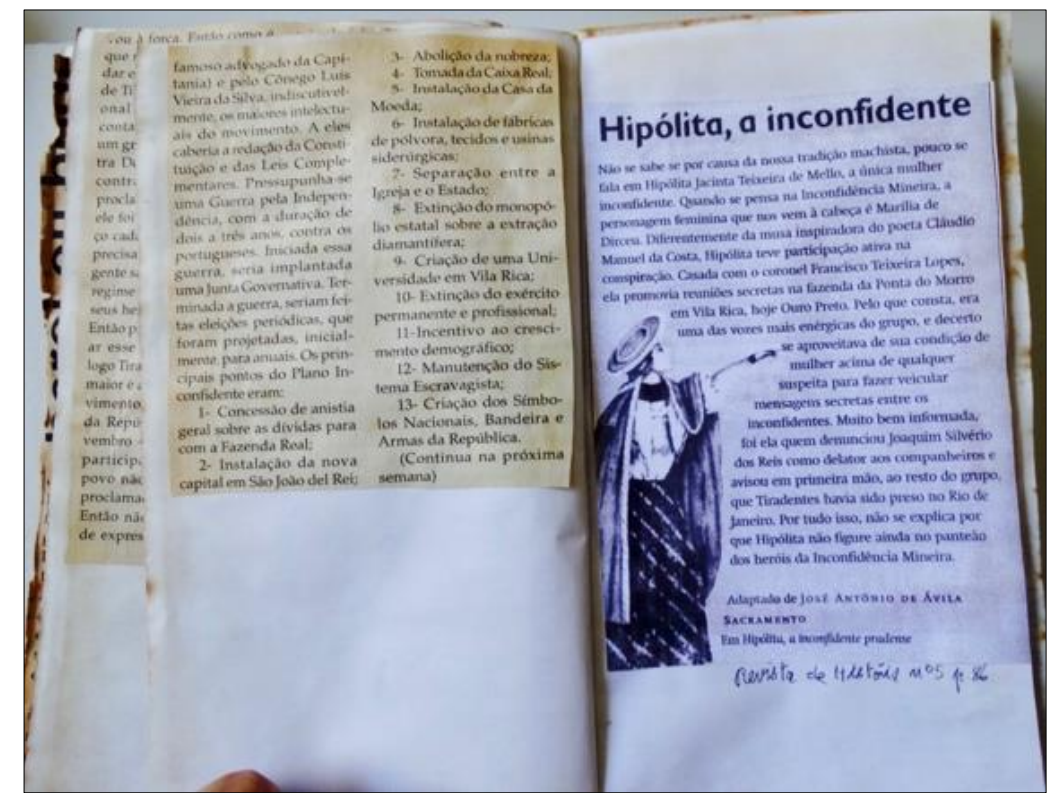

Fonte: Os autores.

Por outro lado, a presença de músicas e filmes, junto ao material pedagógico e historiográfico acumulado oferecem uma visão do modo particular com que esse professor foi compondo o seu acervo. Por certo, as notícias, as músicas e filmes, que ele preservou tenham sido selecionados, tendo em vista a sua utilização didática. Desse modo, supõe-se que estes logo eram convertidos em instrumentos que pudessem contribuir para sensibilizar os seus alunos, por meio da imagem, do movimento e de notícias que tocam os indivíduos em meio aos processos históricos ensinados. Esses produtos culturais, quando transformados em materiais didáticos, também poderiam expandir o foco da história política que, tradicionalmente, vem sendo o eixo sobre o qual se organiza o currículo da disciplina, compondo aqueles conteúdos 
requeridos nos exames de vestibular. Assim, ele não abria mão do enfoque político estrito senso, mas se empenhava em chamar a atenção dos alunos para os costumes, as artes, as relações afetivas e outros aspectos subjetivos da vida social, lembrando que esses aspectos sempre são atravessados pelos processos e eventos políticos de seu tempo.

Como exemplos, a questão da cultura e da contracultura, exemplificadas no movimento hippie dos anos 1960-70, bem como a atenção para outros movimentos de juventudes, tais como o maio de 1968, na França e o fenomenal sucesso dos Beatles. Tais temáticas estão presentes no conjunto documental selecionado pelo Professor Aquino sob a forma de reportagens publicadas em jornais e revistas de grande circulação. Estas constam em seu acervo como referências culturais e políticas sobre as quais todos nós conhecemos e reconhecemos sua importância histórica, mas que, dificilmente, estariam na pauta dos livros didáticos de história que circularam, seja no período anterior seja nos anos que foram coetâneos à sua atuação como professor.

Considerando outros tipos de documento, para além daqueles que seriam diretamente utilizados para compor os conteúdos curriculares das apostilas, encontramos outros itens, tais como poemas, cartas, artigos de revistas, suplementos, mapas, em geral retirados de impressos em circulação em um período de 30, 40 a 50 anos ali contidos. De forma geral, os recortes não se ordenariam por datas e, sim, por temáticas. Os recortes de artigos são sobrepostos em diferentes datas, atualizando discussões e conferindo um aspecto de continuidade nos diferentes presentes da leitura de Aquino, salientando que o aspecto dinâmico das leituras realizadas sobre os temas estava em constante produção ${ }^{12}$. Assim, podemos apontar o caráter dialógico - isto é, relacional e coerente - que esses recortes representam na constituição de conhecimentos considerados relevantes por este professor.

O empenho com o acúmulo de informações resultou na composição de um amplo acervo de conhecimentos, que se pretendia total, se aproximando de um saber de tipo enciclopédico. Tal característica expressa a pressão exercida pelos currículos exigidos pelos exames de pré-vestibular. A grande procura por vagas no ensino superior e a insuficiente oferta, sobretudo nos anos 1970-80, gerou grande pressão social pela ampliação do acesso aos cursos superiores, aumentando as exigências dos exames de ingresso nas Universidades, de modo a equilibrar a distribuição das poucas vagas existentes com base em critérios meritocráticos individuais. De modo articulado, acreditamos, por fim, que a ampliação da carga de conhecimentos exigidos nos exames de ingresso no ensino superior, contribuiu para manter o ensino conteudista e enciclopédico que, ainda hoje, distingue o nível médio dos demais níveis de ensino que compõem a educação básica.

Mas o currículo do ensino médio, em geral, e dos cursos pré-vestibulares, em particular, também devem ser vistos como resultado das concepções e ações partilhadas pelos professores especialistas que influenciavam na composição dos currículos e das provas para seleção dos alunos considerados aptos a ingressarem nas Universidades, públicas, sobretudo. Nesse aspecto, duas tradições de ensino se complementavam e, - ainda que fossem criticadas pelo jovem professor Aquino, não poderiam ser por ele desconsideradas, sob o risco de lhe desautorizar como especialista, tanto na sua área disciplinar quanto no exercício da docência, justo na etapa final do ensino médio.

A primeira tradição se refere ao ensino ministrado na então Faculdade Nacional de Filosofia $(\mathrm{FNFi})^{13}$, no período que antecedeu a Reforma Universitária de 1968. Ainda moldada pelas rígidas hierarquias entre o professor catedrático e seus auxiliares, assim como pelo predomínio do conhecimento erudito, clássico e universalista, a formação do historiador

\footnotetext{
${ }^{12}$ Conforme demonstrou Reinhart Koselleck (2006), tanto o passado quanto o futuro se encontram contidos no presente vivido, seja sob a forma de lembranças de experiências pregressas que orientam nossas decisões, seja nas expectativas que urdimos em nosso presente, para que se materializem no futuro.

${ }^{13}$ A Faculdade Nacional de Filosofia foi criada por Decreto, em abril de 1939, vinculada à Universidade do Brasil, com quatro secções: Ciências; matemática; Química: História Natural; História e Geografia e Ciências Sociais. De acordo com Ferreira (2013), até os anos 1960, a seção de História e Geografia privilegiou a formação do professor de ensino secundário, adotando uma concepção de história nacional, factual, voltada para grandes personagens e seus feitos.
} 
ministrada na FNFi exigia de seus professores e alunos o domínio de amplos conhecimentos. A segunda tradição vem da característica que historicamente definiu o ensino médio como uma marca da educação das elites, daqueles que teriam acesso ao ensino superior e aos mais altos postos de trabalho. Nesse sentido, o currículo de história do ensino médio também trazia as marcas da erudição, acompanhada de uma visão eurocêntrica da história.

$\mathrm{Na}$ próxima seção, abordaremos alguns indícios e desafios postos no trabalho de organização e pesquisa com o Arquivo.

\section{O Arquivo: seus indícios e desafios}

Na parte denominada Biblioteca Pedagógica, a reunião de diferentes suportes dedicados ao estudo da história e ao seu ensino, bem como ao debate sobre a educação em suas dimensões políticas e ideológicas nos remeteu não apenas ao conjunto de itens guardados, mas nos permitiu, também, rastrear algumas de suas práticas de leitura e escrita, visíveis na maneira como ele conduziu a organização de seu material de trabalho. Trata-se dos encadernados em tamanho ofício, com cerca de 300 páginas, a que a equipe inicialmente chamou de dossiê, para, finalmente, atribuir o nome Compêndio.

Esse material é formado por recortes de jornais, textos autorais, artigos das poucas revistas especializadas existentes à época, partes de livros ou qualquer impresso que fosse considerado útil para armazenar e reunir informações sobre temáticas específicas. A ambiência intelectual do período justifica tal criação, na medida em que muitas das temáticas, por sua contemporaneidade ou por seu ineditismo, ainda não contavam com estudos consistentes e disponíveis. A atividade diária de recortar jornais e classificar os dados coletados - já no café da manhã - revelam a entrega deste professor à tarefa diária de organizar, agrupar e dar coerência a elementos que, em seu conjunto, expressam os percursos aparentemente percorridos na preparação de suas inúmeras atividades de mediação intelectual.

Essa ideia nos remeteu ao volume e diversidade de materiais e marcas vistos no Arquivo em tela, dando mostras da aparente incoerência que atravessa documentos textuais, ilustrações, mapas, livros de referência, resumos e listas de conteúdo, entre outros documentos arquivados. Vemos essa cornucópia de materiais, dados e informações que, em algum momento, deixam de sinalizar o caos e adquirem o formato requerido para a identificação do produto cultural a que chamamos pelo nome de livro, em sua configuração final. Borges (1998) considera que a Biblioteca é o resultado de combinações de tudo que é dado a expressar. Mencionamos isso, em associação ao desejo do titular do Arquivo de organizar o que ele lia e recolhia diariamente, produzindo um suporte que julgou apropriado para isso, uma espécie de livro cíclico, o compendio, como uma forma de corroborar outros tantos suportes presentes em sua biblioteca e também para a sua consulta. Torna-se interessante mencionar a existência, no arquivo, de vários amarrados de recortes que não chegaram a ser encadernados, virando, assim um compêndio. Ainda, o fato de estar encadernado não subtrai o caráter cíclico dos compêndios, tendo em vista que em alguns desses suportes eram acrescidos materiais julgados pertinentes às temáticas ali recortadas, mesmo depois de encadernados.

No Arquivo também estão registradas algumas práticas de leitura e de escrita do titular, em marcas que nos permitem perceber a rotina de recortes de suas leituras associada ao intenso diálogo com a renovação da escrita da História, ${ }^{14} \mathrm{e}$ a composição de uma bibliografia pedagógica. Esta observação nos levou a concluir que os inúmeros vestígios das atividades de mediação intelectual às quais Aquino se dedicou em vida -- e que se encontram documentadas em seu Arquivo -- configuram uma prática integrada. Isto porque, as práticas de leitura se associam às ações inscritas na composição dos compêndios, que reúnem dados e

\footnotetext{
${ }^{14} \mathrm{O}$ movimento de renovação historiográfica da época aparece retratado em recortes de jornais, destacando-se as abordagens da história social inglesa, a crítica à história positivista e nacionalista e identificada com um tipo de abordagem marxista mais afeito ao estudo das classes subalternas e ao diálogo interdisciplinar.
} 
informações que alimentam não só o preparo das aulas, mas, também a redação de apostilas e livros didáticos, se fazendo presentes, também, em outras modalidades de textos autorais.

Figura 5 -Foto de um Compêndio aberto. Na colagem, reportagem sobre o Professor Manoel Maurício de Albuquerque, da FNFi, que perdeu o seu posto na instituição após a instauração do regime militar.

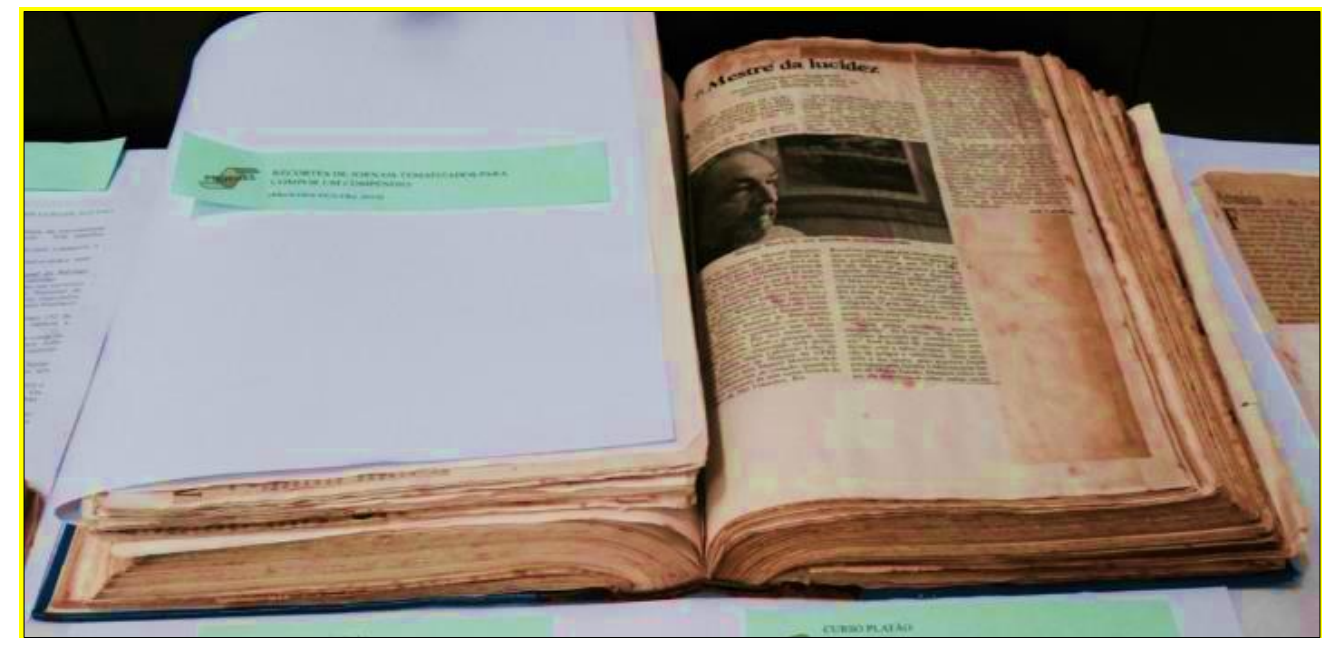

Fonte: os autores.

Nos registros das múltiplas atividades que este professor desenvolveu, há muito de si, de sua identidade como sujeito docente, revelando-se, também a presença da sua rede de sociabilidades. A esse respeito, é interessante observar a mescla de gerações que compõem as redes de sociabilidades com as quais ele interagiu, por meio de citações e referências presentes nos documentos de seu Arquivo, assim como no compartilhamento de autoria de apostilas e livros didáticos. Em primeiro lugar, salta aos olhos as relações de amizade que ele estabeleceu com os antigos professores da FNFi, onde ele se bacharelou, em 1963. Em seguida, notamos a presença de professores dos Cursos onde ele atuou como docente e autor de Apostilas de História para o pré-vestibular. Dessa parceria, alguns autores comparecem em seus livros didáticos, que também conta com coautores das gerações mais jovens, muitos dos quais haviam sido seus alunos.

Por outro lado, o referido Arquivo apresenta muitos desafios, em razão de sua heterogeneidade e diversidade. Trata-se de um fundo que já nos chegou fragmentado, e podemos assim considerá-lo como amostra. Porém, cabe ressaltar o que o que define sua complexidade não é o seu tamanho, -- ou seja, aquele tirado na régua medindo altura, largura e nos dando o alento de sua finitude --, mas a potencialidade que ele representa, despertando em nós essa vontade utópica, como nos aponta Farge (2009), de um dia podermos nos apossar dele exaustivamente. Quando, finalmente, nos deparamos com um conjunto documental sobre o qual se torna possível elaborar a descrição, surge um novo desafio: o de não elaborar interpretações precipitadas, à pressa de uma intimidade forçada.

Para o tratamento e a sistematização do conteúdo arquivado, foi de grande importância a elaboração de uma terminologia controlada e objetiva destinada à identificação dos itens do Arquivo. Esta se faz de modo articulado a uma metodologia de classificação, catalogação e indexação, que não ficaram restritas a áreas como Arquivo e Biblioteconomia, visto que o conjunto documental ali reunido poderia conduzir a usos, interesses e interpretações diversas. Desse modo, nos aproveitamos do fato de estarmos em 
uma equipe multidisciplinar para nos dedicarmos a longos debates sobre a melhor e mais adequada denominação a ser atribuída a cada tipo documental. ${ }^{15}$

No que tange ao material bibliográfico, nossa participação se deu no sentido de verificar itens relativos a "assuntos" presentes na tabela de acesso ao acervo, observando casos de duplicidade e produzindo associações e equivalências para viabilizar futuros acessos aos consulentes. Para a elaboração dos descritores foi necessária a observação, folheio, leitura, processamento de peças relativas aos 322 volumes presentes na referida Biblioteca. Há ainda, pastas que contém apostilas, material didático, e possivelmente proto-materiais que constituiriam volumes de novos compêndios que estavam em fase de processamento, mas não chegaram a ser encadernados. Assim, no trabalho de revisão dos descritores identificados pela equipe para compor a listagem de documentos, nós consideramos, por exemplo, as anotações oriundas das suas reflexões sobre as notícias do momento, no eterno parlatório entre passado e presente, assim como na atenção para artigos que abordavam o debate historiográfico da época, ou daqueles que divulgavam resultados de pesquisas de interesse para as suas atividades docentes e de escrita autoral, entre outras.

Tanta diligência e disciplina do titular do Arquivo se plasmam a um cotidiano dedicado à prática docente e comprometido com a reflexão sobre o momento presente. Aliás, essas duas atividades se encontram associadas de modo inequívoco. $\mathrm{O}$ arquivamento se articula, nesse caso, a uma prática de bricolagem intensa, realizada nas interposições de colagens, de recortes de sua rotina de leitura e de docência a que se somam correspondências, dedicatórias e textos apostilados. Ali há muito de si, quer dizer, de sua subjetividade, mas há também muito de suas concepções sobre a docência, o currículo e as virtualidades formativas da educação escolar. Para além dos documentos guardados, nos chamaram atenção as marcas que o detentor deixou nos livros a serem atualizados, nos roteiros de aula a serem adaptados a diferentes turmas, nos compêndios que embasariam a redação das apostilas e dessas até a transposição de partes para compor os livros didáticos.

Conforme já salientamos, alguns dos desafios enfrentados no trabalho de organização do Arquivo foram percebidos a partir da leitura do texto de Arlette Farge (2009), "O Sabor do Arquivo”. Após o início do processamento do material bibliográfico, ecoaram algumas angústias comuns aos que, além de organizar, também desejam empreender pesquisas no Arquivo com o qual estão interagindo. Um primeiro desafio tem relação com diversidade de tipos que o compõe, onde nos deparamos com a repetição de peças, com muitas sobreposições e colagens, além da necessidade de controlar a expectativa que nos assolou, logo que iniciamos a exploração do Arquivo, de considerar cada detalhe como indício potencial para responder nossas indagações. Mas, na medida em que o percurso da pesquisa avançava, tornou-se possível identificar com mais acuidade o que deveria ser observado para o interesse de nossas questões de acordo com o recorte efetuado no projeto de pesquisa.

\section{Considerações Finais}

O preciosismo de uma rotina moldada pela presença de protocolos de leituras e de práticas de escrita desenha o percurso por meio do qual o material pedagógico contido no Arquivo se engendra com a criação dos livros de sua autoria, a maioria escrito em parceria com outros autores. Desse modo, deixam em relevo sua rede de sociabilidades e suas concepções sobre a história, o seu ensino e a própria experiência de viver. Finalmente, destacamos, como forma de articulação temática e metodológica, que há indícios de uma prática integrada de leitura, escrita e produção de materiais ligados à docência que, ao final, vão resultar na publicação de seus livros autorias, tanto os de caráter didático quanto os de caráter ensaístico.

Por outro lado, é nos vestígios das práticas docentes que nós podemos entender a intensa derivação dela e por ela, em sua imbricação nos protocolos de leitura e nas marcas que

\footnotetext{
${ }^{15} \mathrm{Na}$ equipe, havia dois bolsistas de Iniciação Científica do Instituto de História (Emanoel Germano e Rebecca Rosas) e duas do curso de Pedagogia, além de uma mestranda com formação em Letras, de um membro da área de Arquivo e outro da área de história da educação, como demonstrado na nota 5.
} 
antecedem a escrita e a prática de ensino e que se deixam entrever nos tais Compêndios. A ininterrupta reunião de impressos presentes no seu cotidiano e retidas em seu Arquivo expressa os instantâneos da realidade que ele julgava serem de interesse para o seu trabalho e a sua militância. Nesse ir e vir da observação / organização / tipificação e diálogo com os itens do referido material é que foi se delineando, ainda que imprecisamente para nós, este sujeito leitor, professor, autor em suas múltiplas facetas, na complexidade de seu Arquivo.

O diálogo com a história social da leitura e da escrita, na linha proposta por Roger Chartier (1996), nos instigou a buscar a historicidade dos documentos escritos com atenção para as marcas que indiciam não só a presença do detentor do Arquivo, como os seus modos de interação com os diversos itens arquivados, combinando, initerruptamente, tudo aquilo que ele lê e que pode apresentar utilidade para suas incursões no universo dos conhecimentos históricos.

Por meio de práticas de leitura muito particulares e, ao mesmo tempo, em meio ao campo de possibilidades postas pela renovação historiográfica naqueles anos ${ }^{16}$, o titular do Arquivo articula as bases de sua escrita e produz as suas intepretações, dotando-as de atualidade, coerência e consistência. A tessitura variada dos textos reunidos nesses compêndios atende, assim, às expectativas de produção intelectual e de mediação dos conhecimentos produzidos desde as primeiras leituras do dia, passando pela seleção, classificação e agrupamento das mesmas, até chegar ao ato da escrita, de revisão e de posteriores atualizações.

O modo de apropriação, bem como as estratégias de divulgação de suas publicações demandariam uma análise da produção escrita daí resultante, sua recepção entre alunos e demais professores, bem como as estratégias editoriais de divulgação de seus livros, o que foge aos objetivos deste artigo. Por outro lado, a observação dos modos de compor as suas publicações autorais nos levou a dirigir um olhar sobre os espaços e redes de sociabilidades em que o titular transitou, demonstrando a necessidade de se considerar os múltiplos contextos - intelectual, pedagógico, político, cultural, entre outros - que dão tessitura e se entrelaçam aos textos autorais, tema que demanda a continuidade de nossas pesquisas e, portanto, não será aqui detalhado.

Para além dos desdobramentos deste estudo, nessas considerações finais, cabe assinalar, portanto, que é na configuração dos acervos pessoais que podemos entrever os traços e as pistas de uma trajetória pessoal, mas, também, profissional. Os indícios destacados neste artigo, articulam aspectos como organização das bases do conhecimento a ser configurado em diferentes suportes de arquivamento e de modalidades de escrita, considerando-se, entre estas, as operações de seleção, composição, alteração, reedição, colagens, pós-adições, como primordiais elementos de materialidade das práticas de leitura e de escrita percebidas pelas marcas constitutivas dos itens guardados.

Desse modo e a despeito dos riscos, nós nos empenhamos em compreender o Arquivo pedagógico do Professor Rubin Santos Leão de Aquino como elaboração de si, isto é, da pessoa de seu titular. Mas acreditamos, também, ser possível conhecer mais a respeito da cultura docente, sobretudo da geração de professores de história de cursos preparatórios para o vestibular da zona sul do Rio de Janeiro, que atuou nos anos 1960 1990. Operando por meio de aproximações ou por afastamentos, nós acreditamos ser possível traçar, a partir dos indícios aqui assinalados, um retrato das estruturas de sentimentos que permeavam as expectativas dos professores que articularam docência e militância política, tal como fez Aquino, sempre na companhia de pares que compartilhavam as mesmas utopias, sentimentos e projetos políticos.

Procuramos, assim, ensaiar a articulação entre os diferentes papéis sociais ali evidenciados: o de professor, escritor, produtor de livros didáticos, ativista da profissão

\footnotetext{
${ }^{16}$ Ainda que não tenhamos feito um levantamento minucioso das referências historiográficas presentes em seus escritos, as influências da história social inglesa se fazem notar, por meio de uma abordagem interdisciplinar dos acontecimentos históricos, bem como pelo interesse no estudo da história das classes trabalhadoras, seus costumes e seus movimentos insurgentes.
} 
docente, engajado e militante de várias causas. Entre as suas causas, destacam-se o empenho na disseminação do conhecimento de uma história viva e engajada por meio da educação dos jovens; a expectativa de interferir nos rumos políticos do país e o compartilhamento de uma estrutura de sentimento que envolveu vários professores, artistas e intelectuais da geração que viveu os tempos da repressão imposta pelo regime militar e o processo de construção democrática que se seguiu ao fim desse regime ${ }^{17}$.Como observou Ridenti (2000) se referindo aos artistas dos anos 1960-70, essa estrutura de sentimento se dá a ver na crítica da realidade nacional, associada a uma certa idealização do homem do povo, por seu caráter simples e, em certa medida visto como ingênuo, mas, ao mesmo tempo, prenhe de potencialidades revolucionárias e de genuíno pendor para o engajamento na luta pela construção de uma sociedade fundada na liberdade política e na justiça social. Saudades desses tempos!

\section{Referências}

BAHIA, Bruno. As negociações identitárias do professor de filosofia no Ensino Médio da escola pública no Rio de Janeiro: tempo, experiência e seu lugar na escola. 2016.330f. Tese (Doutorado em Educação) Programa de Pós-Graduação em Educação, Universidade Federal do Rio de Janeiro. Rio de Janeiro, 2016.

BORGES, Jorge Luis. A Biblioteca de Babel. In: BORGES, Jorge Luis. Obras Completas: Ficções.v.1. São Paulo: Editora Globo, 1999.

CERTEAU, Michel de. A invenção do cotidiano: as artes de fazer; 16 Ed., Petrópolis, RJ: Vozes, 2009.

CHARTIER, Roger (Org.) Práticas de leitura. São Paulo: Ed. Liberdade, 1998.

FARGE, Arlette. O sabor do arquivo. São Paulo: Edusp, 2019.

GOMES, Ângela de Castro; HANSEN, Patrícia Santos. Intelectuais Mediadores: Práticas culturais e ação política. Rio de Janeiro: Civilização Brasileira, 2016.489p.

HEYMANN, L. Q. (1997). Indivíduo, memória e resíduo histórico. Estudos Históricos. Rio de Janeiro, CPDOC-FGV, n.19, pp. 41-66.

KOSELLECK, Reinhart. Futuro passado: contribuição à semântica dos tempos históricos. São Paulo: Contraponto, 2006.

MILLS, Charles Wright. Sobre o artesanato intelectual e outros ensaios. Rio de Janeiro: Jorge Zahar Ed, 2009.

RIDENTI, Marcelo. Em busca do povo brasileiro: artistas da Revolução, do CPC à era da TV. Rio de Janeiro-São Paulo: Record, 2000.

SILVA, Amanda. Tempo e docência: dilemas, valores e usos na realidade educacional. Jundiaí: Paco Editorial, 2017.

SIRINELLI, Jean François. Os Intelectuais. In: REMOND, René. (Org.). Por uma história política. Rio de Janeiro: Editora UFRJ-FGV, 1996.

TARDIF, Maurice. Saberes Docentes e Formação Profissional. Petrópolis: Vozes, 2002.

XAVIER, Libania Nacif. Relações e vínculos evocados no ato de ensinar. Tese apresentada à Faculdade de Educação da UFRJ para progressão à categoria de professora titular, outubro de 2018 (mimeo).

\footnotetext{
${ }^{17}$ Sobre o assunto, ver: Ridenti (2000).
} 